\title{
Pregnancy outcomes in women with autism: a nationwide population-based cohort study
}

This article was published in the following Dove Press journal:

Clinical Epidemiology

\author{
Heléne EK Sundelin ${ }^{1,2}$ \\ Olof Stephansson ${ }^{3,4}$ \\ Christina M Hultman ${ }^{5,6}$ \\ Jonas F Ludvigsson ${ }^{5,7-9}$
}

'Department of Pediatrics, Faculty of Medicine and Health, Örebro University, Örebro, Sweden; ${ }^{2}$ Division of Pediatrics, Department of Clinical and Experimental Medicine, Linköping University, Linköping, Sweden; ${ }^{3}$ Clinical Epidemiology Unit, Department of Medicine, Solna, Karolinska University Hospital and Institutet, Stockholm, Sweden; ${ }^{4}$ Department of epidemiology and biostatistics, School of Public Health, University of California, Berkeley, CA, USA; ${ }^{5}$ Department of Medical Epidemiology and Biostatistics, Karolinska Institutet, Stockholm, Sweden; 'Icahn School of Medicine at Mt Sinai, New York, NY, USA; ${ }^{7}$ Department of Pediatrics, Örebro University Hospital, Örebro, Sweden; ${ }^{8}$ Division of Epidemiology and Public Health, School of Medicine, University of Nottingham, Nottingham, UK; ${ }^{9}$ Department of Medicine, Columbia University College of Physicians and Surgeons, New York, NY, USA
Correspondence: Heléne EK Sundelin Department of Pediatrics, Linköping University Hospital, 58I 85 Linköping, Sweden

Tel +46 I0I030000

Email helene.sundelin@liu.se
Background: The consequences of autism in pregnancy outcomes have not been explored before, although it is of crucial importance because of the frequent comorbidities and medication in this group of women.

Objectives: To estimate the risk of adverse pregnancy outcomes in women diagnosed with autism.

Design: Nationwide population-based cohort study.

Setting: Sweden.

Participants: Singleton births identified in the Swedish Medical Birth Registry, 2006-2014. A total of 2,198 births to women diagnosed with autism registered in the Swedish National Patient Registry were compared to 877,742 singleton births to women without such a diagnosis. Main outcome and measures: Preterm delivery. Secondary measures were cesarean delivery (emergency and elective), Apgar score $<7$ at 5 minutes, small for gestational age, large for gestational age, stillbirth, gestational diabetes, and preeclampsia. ORs were calculated through logistic regression, adjusted for maternal age at delivery, maternal country of birth, smoking, maternal body mass index, parity, calendar year of birth, and psychotropic and antiepileptic medication during pregnancy.

Results: Women with autism were at increased risk of preterm birth $(\mathrm{OR}=1.30 ; 95 \%$ $\mathrm{CI}=1.10-1.54)$, especially medically indicated preterm birth $(\mathrm{OR}=1.41 ; 95 \% \mathrm{CI}=1.08-1.82)$, but not with spontaneous preterm birth. Maternal autism was also associated with an increased risk of elective cesarean delivery $(\mathrm{OR}=1.44 ; 95 \% \mathrm{CI}=1.25-1.66)$ and preeclampsia $(\mathrm{OR}=1.34$; 95\% CI=1.08-1.66), but not with emergency cesarean delivery, low Apgar score $(<7)$, large for gestational age, gestational diabetes, and stillbirth. In women with medication during pregnancy, there was no increased risk of adverse pregnancy outcome except for induction of delivery $(\mathrm{OR}=1.33$; 95\% $\mathrm{CI}=1.14-1.55)$.

Conclusion and relevance: Maternal autism is associated with preterm birth, likely due to an increased frequency of medically indicated preterm births, but also with other adverse pregnancy outcomes, suggesting a need for extra surveillance during prenatal care.

Keywords: autism, antiepileptic drugs, pregnancy, preeclampsia, preterm birth

\section{Key points}

Question: Are women with autism at an increased risk of adverse pregnancy outcomes?

Findings: This nationwide population-based cohort study of 2,198 births to 1,382 women diagnosed with autism and 877,742 singleton births to 503,846 women without such a diagnosis found a significantly increased risk of preterm birth, likely due 
to an increased frequency of medically indicated preterm births as well as an increased risk of other adverse pregnancy outcomes.

Meaning: Our results suggest a need for individual prenatal care for women with autism with a better understanding of the difficulties related to autism, especially regarding the communication with health care professionals.

\section{Introduction}

Autism, a disorder with still limited recognition in adult medicine, ${ }^{1}$ is characterized by impairment in social interaction, communication, and restricted, repetitive, stereotyped behavior, interests, and activities. ${ }^{2}$ The etiology of autism is still not fully known, but risk factors include genetic predisposition, structural brain abnormalities with different causes, and physiological and biochemical dysfunction. ${ }^{3}$ Individuals with autism suffer from increased comorbidity (eg, epilepsy and attention-deficit/hyperactivity disorder [ADHD], as well as other psychiatric and somatic disorders) $)^{2,4,5}$ and are often treated with psychotropic and antiepileptic drugs. These drugs, when used during pregnancy are associated with adverse outcomes, such as preterm birth, abnormal birth weight, and poor neonatal adaptation. ${ }^{6-8}$

The reactivity to sensory stimulus (such as pain, touch, and internal changes) is more heightened in individuals with autism and they often show difficulties accommodating to sensory stimuli. ${ }^{9-11}$

While we are aware of two studies on the pregnancy experiences in women with autism (they describe difficulties with sensory processing, adaption to changes during pregnancy, and communication with health care personnel), ${ }^{12,13}$ we have not been able to identify any study on pregnancy outcomes in women with autism.

The aim of this study was to examine the risk of adverse pregnancy outcomes in women with autism. Our main outcome measure was preterm birth as it is strongly associated with fetal maturation, both contributing to higher neonatal mortality and morbidity. ${ }^{14}$

\section{Methods}

Our cohort comprised singleton births from the start of 2006 until the end of $2014(n=954,497)$ recorded in the Swedish Medical Birth Registry (MBR; Figure 1). The MBR has collected information on pre- and perinatal factors since 1973 , with a high validity for the variables used in this study. ${ }^{15}$ The Registry covers more than $98 \%$ of infants born in Sweden. ${ }^{15}$

Through linkage with the Swedish National Patient Registry (NPR) ${ }^{16}$ we were able to identify 2,460 singleton births to women with autism before delivery. Autism was defined according to International Classification of Disease (ICD) codes (ICD-9: 299A, 299B, 299W, 299X; ICD-10: F84.0F84.5, F84.8, and F84.9). To link the registries we used the Swedish personal identity number assigned to all individuals residing in Sweden. ${ }^{16}$ The NPR was introduced in 1964 and became nationwide in $1987 .{ }^{17}$ It includes hospital-based outpatient care since 2001 and today it covers more than $99 \%$ of all hospital discharges. ${ }^{17}$

Singleton births to women never diagnosed with autism were used as population controls. We restricted our study participants to those with complete information on maternal country of birth, smoking in early pregnancy, parity, and selfreported height and weight at the first prenatal visit. These restrictions resulted in a study population of 2,198 births to women with autism and 877,742 to women never diagnosed with autism (Figure 1).

\section{Outcome variables}

From the MBR, we extracted data on completed weeks of gestation, mode of delivery, 5-minute Apgar scores, intrauterine growth, stillbirth, and maternal complications (preeclampsia and gestational diabetes).

Preterm birth was defined as $<37$ completed weeks of gestation. We stratified preterm birth into extremely ( $<28$ weeks), very ( 28 to $<32$ weeks), and moderately ( 32 to $<37$ weeks) preterm birth. Medically indicated preterm birth was defined as preterm delivery after induction of labor or cesarean section before labor. Cesarean delivery was divided into elective (an existing variable in the MBR) and not elective. Low 5-minute Apgar score was defined as a score $<7$. We used the Swedish sex-specific estimated fetal growth curves ${ }^{18}$ to define small for gestational age (SGA) birth as having a birth weight less than two standard deviations below the mean birth weight for their gestational age, and large for gestational age (LGA) birth as having a birth weight of two standard deviations above the mean birth weight for their gestational age. Stillbirth was defined as fetal death at $\geq 28$ completed gestational weeks until 2008 and thereafter, $\geq 22$ completed gestational weeks. We defined maternal preeclampsia and gestational diabetes as having relevant ICD-10 codes (preeclampsia: O14-15 and gestational diabetes: O244). ICD-10 was introduced in Sweden in 1997.

\section{Variables used for adjusted calculations}

Maternal age at delivery ( $\leq 24,25-29,30-34, \geq 35$ years), maternal country of birth (Nordic [Sweden, Denmark, Norway, Finland, and Iceland] vs non-Nordic country), calendar year of 


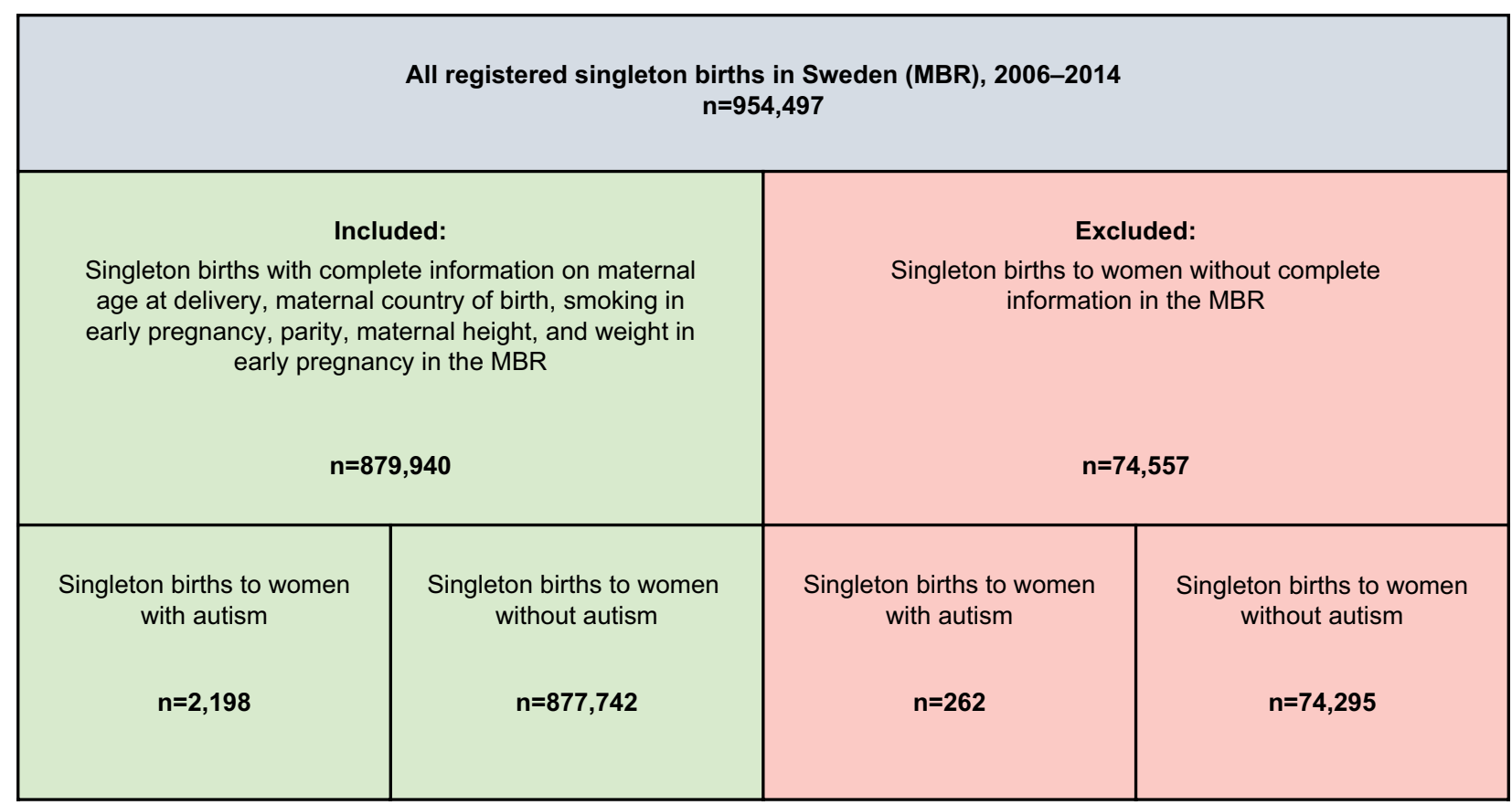

Figure I Study cohort, definition, and exclusion.

Notes: The study cohort was defined using the Swedish MBR. Autism was defined per the ICD codes (ICD-9: 299A, 299B, 299W, 299X; ICD-I0: F84.0-F84.5, F84.8, and F84.9).

Abbreviations: ICD, International Classification of Disease; MBR, Medical Birth Register.

birth (1997-2001, 2002-2006, 2007-2011), smoking in early pregnancy (nonsmoker, 1-9 cigarettes/day, $\geq 10$ cigarettes/day), and parity (primipara or multipara) were all extracted from the MBR. Body mass index (BMI; $<18.5,18.5$ to $<25,25$ to $<30$, and $\geq 30$ ) was calculated from self-reported height and weight at the first prenatal visit in the MBR. At the time of this writing, there are no approved drugs for autism in Sweden and we considered the use of psychotropic and antiepileptic medication as a treatment for a comorbid disease. Data on psychotropic (antipsychotic, hypnotic/anxiolytic, antidepressant, and to treat ADHD) and antiepileptic medication were obtained through the Swedish Prescribed Drug Registry, which includes information on all dispensed drugs since July 1, 2005, registered as Anatomical Therapeutic Chemical (ACT) codes. ${ }^{19}$ The drugs included according to ACT codes are described in Table S1. Medication during pregnancy was defined as drugs dispensed $<6$ months before conception until birth date.

\section{Analytics}

We calculated crude (ORs) and adjusted odds ratios (aORs) with $95 \%$ CIs using unconditional logistic regression adjusted for maternal age, country of maternal birth, smoking, BMI, parity, year of birth, psychotropic and antiepileptic medication during pregnancy to control for confounding. In the main analyses for both women with autism and population controls, more than one birth per woman was allowed. In a separate analysis, we calculated ORs and aOR (adjusted as described above except for parity) for primiparous women with autism and their controls. For biparous women we calculated the risk of preeclampsia to be able to further explore the described link between autism and preeclampsia. ${ }^{20}$ As sensitivity analyses we stratified births to women with and without psychotropic and antiepileptic medication during pregnancy and calculated crude and adjusted OR for adverse pregnancy outcomes.

Data were analyzed using SPSS software, version 24.

\section{Ethics}

The study was approved by the Regional Ethics Committee in Stockholm, Sweden (2008/1182-31/4). Formal individual consent was not required due to the strict registry-based study design. ${ }^{21}$

\section{Results}

\section{Characteristics of study participants}

After exclusions, as described above, our cohort consisted of 2,198 births to 1,382 women with autism and 877,742 births to 503,846 women never diagnosed with autism (Figure 1). 
Women with autism were more often smokers and primipara than control women (Table 1). They were also younger at delivery than the controls (median age 26.0 vs 30 years). Additional characteristics are listed in Table 1 . In $>45 \%$ of births to women with autism, psychotropic or antiepileptic drugs were used during the pregnancies (Table 1). For a detailed description of medication before and during pregnancy, see Table 1.

\section{Main results}

Women with autism were at an increased risk of preterm birth $(\mathrm{OR}=1.30 ; 95 \% \mathrm{CI}=1.10-1.54)$, which after stratification, remained for moderately (32 to $<37$ weeks) preterm birth $(\mathrm{OR}=1.32 ; 95 \% \mathrm{CI}=1.10-1.58$; Table 2$)$. In primiparous women with autism, the risk remained significantly increased only for moderately preterm birth (Table 3). This finding was due to the excess risk of medically indicated preterm birth $(\mathrm{OR}=1.41 ; 95 \% \mathrm{CI}=1.08-1.82)$, whereas there was no increased risk of spontaneous preterm birth (Tables 2 and 3 ). Women with autism and without preeclampsia were at an increased risk of medically indicated preterm birth $(\mathrm{aOR}=1.59,95 \% \mathrm{CI}=1.42-1.78)$.

Maternal autism was also linked with an increased risk of elective cesarean delivery in births to women with autism $(\mathrm{OR}=1.44 ; 95 \% \mathrm{CI}=1.25-1.66)$ and in primiparous women with autism $(\mathrm{OR}=1.85 ; 95 \% \mathrm{CI}=1.52-2.25$; Tables 2 and 3 ).

Preeclampsia was more prevalent in mothers with autism (Table 2). In the sensitivity analyses (Table 3), the risk of preeclampsia was not significantly increased for primiparous women although it was for biparous women with autism $(\mathrm{aOR}=2.23 ; 95 \% \mathrm{CI}=1.43-3.46)$. The risk of induction of delivery was increased in birth to women with autism $(\mathrm{OR}=1.52 ; 95 \% \mathrm{CI}=1.37-1.70)$.

Table I Characteristics of the studied women with singleton births (2006-20I4) divided into groups

\begin{tabular}{|c|c|c|c|}
\hline & & $\begin{array}{l}\text { Births to women } \\
\text { with autism, n (\%) }\end{array}$ & $\begin{array}{l}\text { Births to population } \\
\text { controls, } \mathbf{n}(\%)\end{array}$ \\
\hline & & 2,198 & 877,742 \\
\hline Maternal age, years & $\leq 24$ & 878 (39.9) & $127,078(\mid 4.5)$ \\
\hline & $25-29$ & $621(28.3)$ & $257,263(29.3)$ \\
\hline & $30-34$ & $469(21.3)$ & $302,892(34.5)$ \\
\hline & $\geq 35$ & $230(10.5)$ & $190,500(21.7)$ \\
\hline Parity & Primipara & I, I 75 (53.5) & $389,278(44.3)$ \\
\hline & Multipara & I,023 (46.5) & $488,464(55.7)$ \\
\hline Maternal country of birth & Nordic & $2,05 I(93.3)$ & 683,405 (77.9) \\
\hline & Non-Nordic & $147(6.7)$ & $194,337(22.1)$ \\
\hline $\mathrm{BMI}^{\mathrm{a}}$ & $<18.5$ & $93(4.2)$ & $21834(2.5)$ \\
\hline & 18.5 to $<25$ & I, I I 4 (50.7) & $527,724(60.2)$ \\
\hline & 25 to $<30$ & $549(25.0)$ & $218,14 \mid(24.9)$ \\
\hline & $\geq 30$ & $440(20.0)$ & $108,245(12.4)$ \\
\hline Calendar year of birth & 2006-2008 & $64 \mid(29.2)$ & 273,639 (31.2) \\
\hline & 2009-20II & $726(33.0)$ & $299,362(34.1)$ \\
\hline & $2012-2014$ & $831(37.8)$ & $304,74 \mathrm{I}(34.7)$ \\
\hline Smoking in early pregnancy & Nonsmoker & I,744 (79.3) & $821,745(93.6)$ \\
\hline & I-9 cigarettes/day & $308(14.0)$ & $43,531(5.0)$ \\
\hline & $\geq 10$ cigarettes/day & $146(6.6)$ & $12,466(1.4)$ \\
\hline Antiepileptic drugs & Anytime & $738(33.6)$ & $35,323(4.0)$ \\
\hline & Before & $332(15.1)$ & $12,187(1.4)$ \\
\hline & During & $15 \mid(6.9)$ & $5,729(0.7)$ \\
\hline Antipsychotics & Anytime & I,769 (80.5) & $229,893(26.2)$ \\
\hline Hypnotics/anxiolytics & Before & $\mathrm{I}, 090(49.6)$ & $101,139(11.5)$ \\
\hline & During & $595(27.1)$ & $36,193(4.1)$ \\
\hline Antidepressants & Anytime & $1,909(86.9)$ & $214,340(24.4)$ \\
\hline & Before & $\mathrm{I}, 244(56.6)$ & $94,384(10.8)$ \\
\hline & During & $808(36.8)$ & $44,343(5.1)$ \\
\hline Antiepileptic drugs, antipsychotics, & Anytime & $2,027(92.2)$ & $304,911(34.7)$ \\
\hline hypnotics/anxiolytics antidepressants & Before & $\mathrm{I}, 424(64.8)$ & $143,380(16.3)$ \\
\hline & During & $\mathrm{I}, 007(45.8)$ & $67,508(7.7)$ \\
\hline
\end{tabular}

Note: ${ }^{\mathrm{B}} \mathrm{BMI}$ do not add up in numbers. Abbreviation: BMI, body mass index. 
Table 2 Adverse pregnancy outcomes in singleton births to women with autism, Sweden, 2006-2014

\begin{tabular}{|c|c|c|c|c|c|}
\hline \multicolumn{2}{|l|}{ Outcome variables } & \multirow{2}{*}{$\begin{array}{l}\begin{array}{l}\text { Cases in } \\
\text { women }\end{array} \\
\text { with autism } \\
(n=2,196)\end{array}$} & \multirow{2}{*}{$\begin{array}{l}\text { Cases in } \\
\text { population } \\
\text { controls } \\
(n=875,944)\end{array}$} & \multirow{2}{*}{$\begin{array}{l}\text { Crude OR; } \\
95 \% \mathrm{CI} \\
1.45 ; 1.23-I .7 I\end{array}$} & \multirow{2}{*}{$\begin{array}{l}\text { Adjusted OR; } \\
95 \% \mathrm{Cl} \\
\text { I.30; I. I0-1.54 }\end{array}$} \\
\hline Preterm birth & Preterm birth, all & & & & \\
\hline & Preterm birth $<28$ weeks & $6(0.3)$ & $2,148(0.2)$ & I.I2; 0.50-2.49 & $1.03 ; 0.46-2.30$ \\
\hline & Preterm birth 28 to $<32$ weeks & $13(0.6)$ & $3,805(0.4)$ & I.36; 0.79-2.36 & $1.24 ; 0.72-2.14$ \\
\hline & Preterm birth 32 to $<37$ weeks & $128(5.8)$ & $38,388(4.0)$ & $1.47 ; 1.23-1.76$ & $1.32 ; 1.10-1.58$ \\
\hline & Spontaneous preterm birth & $87(4.0)$ & $25,348(2.9)$ & I.38; I.I2-I.7I & $1.23 ; 0.99-1.52$ \\
\hline & Medically indicated preterm birth & $59(2.7)$ & $15,612(1.8)$ & $1.52 ; 1.17-1.97$ & $I .4 I ; 1.08-I .82$ \\
\hline \multirow[t]{4}{*}{ Mode of delivery } & Cesarean delivery & $395(18.0)$ & $145,782(16.6)$ & I.10; 0.98-1.22 & $1.25 ; 1.12-1.40$ \\
\hline & Elective cesarean delivery & $217(9.9)$ & $73,844(8.4)$ & $1.19 ; 1.04-1.37$ & $1.44 ; 1.25-1.66$ \\
\hline & Not elective cesarean delivery & $178(8.1)$ & $71,938(I 1.2)$ & $0.99 ; 0.85-1.15$ & $1.03 ; 0.88-1.21$ \\
\hline & Induction of delivery, all & $431(19.6)$ & $117,837(13.5)$ & $1.57 ; 1.4 I-I .75$ & $1.52 ; 1.37-1.70$ \\
\hline Apgar score & Apgar score $<7$ at 5 minutes & $34(1.5)$ & $|I I, 23|(I .3)$ & $1.21 ; 0.86-1.70$ & $1.13 ; 0.80-1.58$ \\
\hline \multirow[t]{2}{*}{ Intrauterine growth } & SGA & $250(I I .5)$ & $83,077(9.5)$ & $1.23 ; 1.08-1.40$ & $1.13 ; 0.99-1.30$ \\
\hline & LGA & $215(9.8)$ & $86,720(9.9)$ & $0.99 ; 0.86-1.14$ & $1.00 ; 0.87-1.16$ \\
\hline Stillbirth & Stillbirth & $6(0.3)$ & $2,628(0.3)$ & $0.9 \mathrm{I} ; 0.4 \mathrm{I}-3.03$ & $0.86 ; 0.39-1.93$ \\
\hline Maternal & Preeclampsia & $91(4.1)$ & $23,713(2.7)$ & $1.55 ; 1.26-1.92$ & $1.34 ; 1.08-1.66$ \\
\hline complications & Gestational diabetes & $27(1.2)$ & 9,919 (I.I) & I.10; 0.74-1.59 & $1.30 ; 0.89-1.91$ \\
\hline
\end{tabular}

Notes: Data are $n$ (\%) unless otherwise specified. Statistically significant risk estimates are italicized and bold. a ${ }^{\circ}$ Rs were adjusted for maternal age, country of maternal birth, smoking, body mass index, parity, year of birth, psychotropic, and antiepileptic medication during pregnancy.

Abbreviations: LGA, large for gestational age; SGA, small for gestational age.

Table 3 Adverse pregnancy outcomes in singleton births to primiparous women with autism, Sweden, 2006-2014

\begin{tabular}{|c|c|c|c|c|c|}
\hline \multicolumn{2}{|c|}{ Outcome variables } & \multirow{2}{*}{$\begin{array}{l}\begin{array}{l}\text { Women } \\
\text { with autism, } \\
n=I, 174\end{array} \\
85(7.2)\end{array}$} & \multirow{2}{*}{$\begin{array}{l}\text { Cases in population } \\
\text { controls } n=388,542\end{array}$} & \multirow{2}{*}{$\begin{array}{l}\text { Crude OR; } \\
95 \% \mathrm{CI} \\
1.29 ; 1.03-1.60\end{array}$} & \multirow{2}{*}{$\begin{array}{l}\text { Adjusted OR; } \\
\text { 95\% Cl } \\
1.24 ; 0.99-1.55\end{array}$} \\
\hline Preterm birth & Preterm birth, all & & & & \\
\hline & Preterm birth $<28$ weeks & $2(0.2)$ & $\mathrm{I}, 20 \mathrm{I}(0.3)$ & $0.55 ; 0.14-2.20$ & $0.52 ; 0.13-2.09$ \\
\hline & Preterm birth 28 to $<32$ weeks & $8(0.7)$ & $2,122(0.5)$ & I.25; 0.62-2.5। & $1.23 ; 0.61-2.47$ \\
\hline & Preterm birth 32 to $<37$ weeks & $75(6.4)$ & $18,905(4.9)$ & $1.33 ; 1.06-1.69$ & $1.28 ; 1.17-1.62$ \\
\hline & Spontaneous preterm birth ${ }^{\mathrm{b}}$ & $54(4.6)$ & $14,254(3.7)$ & $1.27 ; 0.96-1.66$ & $1.22 ; 0.93-1.61$ \\
\hline & Medically indicated preterm birth ${ }^{\mathrm{b}}$ & $30(2.6)$ & $7,789(2.0)$ & $1.28 ; 0.89-1.84$ & $1.24 ; 0.86-1.78$ \\
\hline \multirow[t]{4}{*}{ Mode of delivery } & Cesarean delivery & $233(19.8)$ & $72,014(18.5)$ & $1.09 ; 0.94-1.26$ & I.33; I.15-I.54 \\
\hline & Elective cesarean delivery & $113(9.6)$ & $25,370(6.5)$ & $1.52 ; 1.26-1.85$ & I.85; I.52-2.25 \\
\hline & Not elective cesarean delivery & $120(10.2)$ & $46,644(12.0)$ & $0.84 ; 0.69-1.01$ & $0.99 ; 0.82-1.20$ \\
\hline & Induction of delivery, all & $201(17.1)$ & $58,194(15.0)$ & $1.17 ; 1.00-1.36$ & $1.22 ; 1.04-1.42$ \\
\hline Apgar score & Apgar score $<7$ at 5 minutes & $22(1.9)$ & $6,429(1.7)$ & I.14; 0.74-I.73 & $1.11 ; 0.73-1.70$ \\
\hline \multirow{2}{*}{$\begin{array}{l}\text { Intrauterine } \\
\text { growth }\end{array}$} & SGA & $159(13.6)$ & $50,985(13.2)$ & $1.04 ; 0.88-1.22$ & $1.05 ; 0.88-1.24$ \\
\hline & LGA & $78(6.7)$ & $23,467(6.1)$ & I.II; 0.88-1.39 & $1.01 ; 0.80-1.28$ \\
\hline Stilbirth & Stillbirth & $3(0.3)$ & $1,269(0.3)$ & $0.78 ; 0.25-2.43$ & $0.75 ; 0.24-2.32$ \\
\hline Maternal & Preeclampsia & $63(5.4)$ & $16,333(4.2)$ & $1.29 ; 1.00-1.67$ & $1.21 ; 0.94-1.56$ \\
\hline complications & Gestational diabetes & $16(1.4)$ & $3,624(0.9)$ & I.47; 0.90-2.4I & I.66; I.0I-2.74 \\
\hline
\end{tabular}

Notes: Data are $\mathrm{n}(\%)$ unless otherwise specified. Statistically significant risk estimates are italicized and bold. ${ }^{\mathrm{a} O R s}$ were adjusted for maternal age, country of maternal birth, smoking, body mass index, parity, and year of birth. 'be did not have data on spontaneous vs induced preterm birth in all preterm births, hence numbers do not add up. Abbreviations: LGA, large for gestational age; SGA, small for gestational age.

Other pregnancy outcomes, including gestational diabetes, were not linked to maternal autism in the main analyses, except for SGA in women without medication during pregnancy $(\mathrm{OR}=1.23 ; 95 \% \mathrm{CI}=1.02-1.47$; Table $\mathrm{S} 2)$.
In women with medication during pregnancy, there was no increased risk of adverse pregnancy outcomes except for induction of delivery $(\mathrm{OR}=1.33 ; 95 \% \mathrm{CI}=1.14-1.55$; Table S3). 


\section{Discussion}

\section{Main findings}

This nationwide population-based cohort study of 2,198 births found a positive association between maternal autism and preterm birth in the offspring. This is important as preterm birth is a major cause of morbidity and mortality in the neonatal period..$^{22,23}$

Preterm birth has been linked with several maternal conditions including preeclampsia, chronic hypertension, a history of preterm birth and lung disease, age $>30$ years, and stress (both physiologic and psychologic). ${ }^{23,24}$ Women with autism in our cohort were significantly younger than the controls and had no increased risk of gestational diabetes. Women with autism and without preeclampsia were at an even higher risk of medically indicated preterm birth than women with autism in general. Hence, these factors are unlikely to explain the excess risk of preterm birth seen in mothers with autism in our cohort, due to an increased risk of medically indicated preterm birth and moderately (32 to $<37$ weeks) preterm birth. We found no increased risk of spontaneous preterm birth.

Women with autism with psychotropic and antiepileptic medication during pregnancy were not at an increased risk of preterm birth compared with population controls on the same medication. However, a slightly higher percentage of women with autism with psychotropic and antiepileptic medication than those without these medications had an adverse pregnancy outcome. It is possible that women with autism undergoing treatment have a more severe form of autism. Continuation of psychotropic medication during pregnancy has not earlier been associated with adverse pregnancy outcomes. ${ }^{25-27}$

Women with autism in our study had a 1.3 -fold risk of preeclampsia in our main analyses. In the sensitivity analyses, the risk was not significantly increased for primiparous women; nevertheless, biparous women with autism had a 2.3-fold risk for preeclampsia. Preeclampsia is considered to be caused by an exaggerated systemic inflammatory response. ${ }^{28}$ Thus, it is possible that an altered immune response in individuals with autism ${ }^{29}$ contributed to the higher prevalence of preeclampsia.

There has not been reported any differences in risk of adverse pregnancy outcome in women who discontinued antipsychotic medication during pregnancy compared with those who continued..$^{26,27}$ Hence, the use of antipsychotic and hypnotic/anxiolytic drugs during pregnancy might reflect a more severe autism in these women.

Supported by our findings of an increased risk of elective cesarean and induction of delivery, as well as no increased risk of extremely ( $<28$ weeks) or very ( 28 to $<32$ weeks) preterm delivery, low 5 minutes Apgar score, and emergency cesarean delivery, there might be a wish to commence the delivery more dependent on the mothers' than fetal wellbeing. The difficulties with heightened sensitivity to sensory stimuli, internal changes, and difficulties to adapt to these in women with autism, ${ }^{9-13}$ might impose a stronger stress response and thereby contribute to the increased risk of elective cesarean delivery and labor induction. Another reason might be the difficulties in communication between health care personnel and patients with autism. ${ }^{30}$ The continuation of psychotropic medication during pregnancy could potentially ameliorate these difficulties.

Studies have proposed preeclampsia, labor induction, and SGA as risk factors for autism in offspring. ${ }^{5,20,31-33}$ Since autism is a highly inherited disease with only partial penetrance, it is possible that preeclampsia, labor induction, and SGA are signs of overlapping inheritance.

\section{Strengths and limitations}

One strength of our study is the large number of pregnant women, which allowed us to calculate precise risk estimates. We used a population-based approach to minimize selection bias. We were also able to adjust our data for a number of covariates (although residual confounding can never fully be ruled out in observational studies). Most of the data on confounders were collected prospectively before the outcome of the study, thereby excluding recall bias. ${ }^{15}$ Birth data were retrieved from a registry with high validity (the Swedish MBR).

Our study has some limitations. First, a small number of women with mild autism may never have been admitted to a hospital or visited a hospital-based outpatient clinic (and thus have no diagnosis of autism in the NPR); however, this is unlikely because most patients with autism are diagnosed by specialists. Moreover, such a misclassification will lead only to false-negative cases (then classified as healthy controls) but considering the low prevalence of autism, false-negative autism is unlikely to influence our risk estimates more than marginally. A second limitation is the lack of validation of autism in our cohort. However, the NPR has a high positive predictive value $(85 \%-95 \%)$ for most chronic disorders including different psychiatric disorders. ${ }^{17} \mathrm{~A}$ third limitation is the lack of information on life circumstances since medication during pregnancy might be less common in women with autism who are living in a less caring environment (individuals with autism often depend on others to communicate and understand their needs). ${ }^{30}$ Furthermore, we cannot rule out that communication difficulties have influenced our risk 
estimates for adverse pregnancy outcomes. On the other hand, the need for medication might be concealed in individuals living in a supporting and caring environment by reduced symptoms of psychiatric comorbidities.

\section{Conclusion}

Maternal autism was linked with preterm birth, probably due to an increased frequency of medically indicated preterm births, but also with other adverse pregnancy outcomes, such as increased risk of preeclampsia. In the group who continued with psychotropic medication only, the increased risk of preeclampsia remained significant. Our results suggest a need for individual prenatal care for women with autism, weighing pros and cons for continuation of psychotropic medication, with a better understanding of the difficulties related to autism, especially regarding the communication with health care professionals.

\section{Acknowledgments}

This study was supported by grants from the Swedish Research Council (2013-2429), the Swedish Research Council for Health Working Life and Welfare (2015-01369), and by grants provided by the Stockholm County Council (ALF project 20130156). The funding agencies had no influence on the study design, conduct, or reporting.

\section{Disclosure}

The authors report no conflicts of interest in this work.

\section{References}

1. Zerbo O, Massolo ML, Qian Y, Croen LA. A study of physician knowledge and experience with autism in adults in a large integrated healthcare system. J Autism Dev Disord. 2015;45(12):4002-4014.

2. Lai MC, Lombardo MV, Baron-Cohen S. Autism. Lancet. 2014; 383(9920):896-910.

3. Moreno-De-Luca A, Myers SM, Challman TD, Moreno-De-Luca D, Evans DW, Ledbetter DH. Developmental brain dysfunction: revival and expansion of old concepts based on new genetic evidence. Lancet Neurol. 2013;12(4):406-414.

4. Selassie AW, Wilson DA, Martz GU, Smith GG, Wagner JL, Wannamaker BB. Epilepsy beyond seizure: a population-based study of comorbidities. Epilepsy Res. 2014;108(2):305-315.

5. Cawthorpe D. Comprehensive description of comorbidity for autism spectrum disorder in a general population. Perm J. 2017;21:16-088.

6. Sadowski A, Todorow M, Yazdani Brojeni P, Koren G, Nulman I. Pregnancy outcomes following maternal exposure to second-generation antipsychotics given with other psychotropic drugs: a cohort study. $B M J$ Open. 2013;3(7):e003062.

7. Huang H, Coleman S, Bridge JA, Yonkers K, Katon W. A meta-analysis of the relationship between antidepressant use in pregnancy and the risk of preterm birth and low birth weight. Gen Hosp Psychiatry. 2014;36(1):13-18.

8. Pennell PB. Use of antiepileptic drugs during pregnancy: evolving concepts. Neurotherapeutics. 2016;13(4):811-820.
9. Baranek GT, David FJ, Poe MD, Stone WL, Watson LR. Sensory Experiences Questionnaire: discriminating sensory features in young children with autism, developmental delays, and typical development. J Child Psychol Psychiatry. 2006;47(6):591-601.

10. Marco EJ, Hinkley LB, Hill SS, Nagarajan SS. Sensory processing in autism: a review of neurophysiologic findings. Pediatr Res. 2011;69(5 Pt2): 48R-54R.

11. Green SA, Hernandez L, Tottenham N, Krasileva K, Bookheimer SY, Dapretto M. Neurobiology of sensory overresponsivity in youth with autism spectrum disorders. JAMA Psychiatry. 2015;72(8):778-786.

12. Rogers C, Lepherd L, Ganguly R, Jacob-Rogers S. Perinatal issues for women with high functioning autism spectrum disorder. Women Birth. 2017;30(2):e89-e95.

13. Gardner M, Suplee PD, Bloch J, Lecks K. Exploratory study of childbearing experiences of women with Asperger Syndrome. Nurs Womens Health. 2016;20(1):28-37.

14. Wilcox AJ, Weinberg CR, Basso O. On the pitfalls of adjusting for gestational age at birth. Am J Epidemiol. 2011;174(9):1062-1068.

15. Källén B, Källén K. The Swedish Medical Birth Register - a summary of content and quality. Sweden: Socialstyrelsen. 2003.

16. Ludvigsson JF, Otterblad-Olausson P, Pettersson BU, Ekbom A. The Swedish personal identity number: possibilities and pitfalls in healthcare and medical research. Eur J Epidemiol. 2009;24(11):659-667.

17. Ludvigsson JF, Andersson E, Ekbom A, et al. External review and validation of the Swedish national inpatient register. BMC Public Health. 2011;11:450.

18. Marsál K, Persson PH, Larsen T, Lilja H, Selbing A, Sultan B. Intrauterine growth curves based on ultrasonically estimated foetal weights. Acta Paediatr. 1996;85(7):843-848.

19. Wettermark B, Hammar N, Fored CM, et al. The new Swedish Prescribed Drug Register - opportunities for pharmacoepidemiological research and experience from the first six months. Pharmacoepidemiol Drug Saf. 2007;16(7):726-735.

20. Dachew BA, Mamun A, Maravilla JC, Alati R. Pre-eclampsia and the risk of autism-spectrum disorder in offspring: meta-analysis. $\mathrm{Br} J$ Psychiatry. 2018;212(3):142-147.

21. Ludvigsson JF, Håberg SE, Knudsen GP, et al. Ethical aspects of registry-based research in the Nordic countries. Clin Epidemiol. 2015;7:491-508.

22. Simic M, Amer-Wåhlin I, Lagercrantz H, Maršál K, Källén K. Survival and neonatal morbidity among extremely preterm born infants in relation to gestational age based on the last menstrual period or ultrasonographic examination. J Perinat Med. 2014;42(2):247-253.

23. Behrman RE, Butler AS, editors. Preterm Birth: Causes, Consequences, and Prevention. The National Academies Collection: Reports funded by National Institutes of Health. Washington (DC): National Academies Press; 2007.

24. Moutquin JM. Socio-economic and psychosocial factors in the management and prevention of preterm labour. BJOG. 2003;110(Suppl 20):56-60.

25. Cantarutti A, Merlino L, Monzani E, Giaquinto C, Corrao G. Is the risk of preterm birth and low birth weight affected by the use of antidepressant agents during pregnancy? A population-based investigation. PLoS One. 2016;11(12): $\mathrm{e} 0168115$.

26. Petersen I, McCrea RL, Sammon CJ, et al. Risks and benefits of psychotropic medication in pregnancy: cohort studies based on UK electronic primary care health records. Health Technol Assess. 2016;20(23):1-176.

27. Frayne J, Nguyen T, Bennett K, Allen S, Hauck Y, Liira H. The effects of gestational use of antidepressants and antipsychotics on neonatal outcomes for women with severe mental illness. Aust $N Z$ J Obstet Gynaecol. 2017;57(5):526-532.

28. Steegers EA, von Dadelszen P, Duvekot JJ, Pijnenborg R. Pre-eclampsia. Lancet. 2010;376(9741):631-644

29. Szachta P, Skonieczna-Żydecka K, Adler G, Karakua-Juchnowicz $\mathrm{H}$, Madlani H, Ignyś I. Immune related factors in pathogenesis of autism spectrum disorders. Eur Rev Med Pharmacol Sci. 2016;20(14): 3060-3072. 
30. Nicolaidis C, Raymaker D, McDonald K, et al. Comparison of healthcare experiences in autistic and non-autistic adults: a cross-sectional online survey facilitated by an academic-community partnership. J Gen Intern Med. 2013;28(6):761-769.

31. Gregory SG, Anthopolos R, Osgood CE, Grotegut CA, Miranda ML. Association of autism with induced or augmented childbirth in North Carolina Birth Record (1990-1998) and Education Research (1997-2007) databases. JAMA Pediatr. 2013;167(10):959-966.
32. Mann JR, McDermott S, Bao H, Hardin J, Gregg A. Pre-eclampsia, birth weight, and autism spectrum disorders. J Autism Dev Disord. 2010;40(5):548-554.

33. Walker CK, Krakowiak P, Baker A, Hansen RL, Ozonoff S, HertzPicciotto I. Preeclampsia, placental insufficiency, and autism spectrum disorder or developmental delay. JAMA Pediatr. 2015;169(2): 154-162. 


\section{Supplementary materials}

Table SI ACT codes used in the study

\begin{tabular}{|c|c|c|}
\hline Drug & ACT-code & \\
\hline Antiepileptic drugs & $\begin{array}{l}\text { N03AF0I } \\
\text { N03AF02 } \\
\text { N03AX09 } \\
\text { N03AXI4 }\end{array}$ & $\begin{array}{l}\text { Phenobarbital, Phenytoin, Fosphenytoin, Ethosuximide, Clonazepam, Carbamazepine, Oxcarbazepine, } \\
\text { Rufinamide, Eslicarbazepine, Valproate, Vigabatrin, Lamotrigine, Felbamate, Topiramate, Gabapentin, } \\
\text { Levetiracetam, Zonisamide, Pregabalin, Stiripentol, Lacosamide, Retigabine, Perampanel, Brivaracetam } \\
\text { Carbamazepine } \\
\text { Oxcarbazepine } \\
\text { Lamotrigine } \\
\text { Levetiracetam }\end{array}$ \\
\hline Antipsychotics & N05A & $\begin{array}{l}\text { Levomepromazine, Fluphenazine, Perphenazine, Haloperidol, Melperone, Droperidol, Sertindole, } \\
\text { Ziprasidone, Lurasidone, Flupentixol, Chlorprothixene, Zuclopenthixol, Loxapine, Clozapine, } \\
\text { Olanzapine, Kvetiapin, Lithium, Risperidone, Aripiprazole, Paliperidone, Brexpiprazole }\end{array}$ \\
\hline Hypnotics/anxiolytics & N05B/N05C & $\begin{array}{l}\text { Diazepam, Oxazepam, Lorazepam, Alprazolam, Hydroxyzine, Buspirone, Nitrazepam, } \\
\text { Flunitrazepam, Midazolam, Zopiclone, Zolpidem, Melatonin, Clomethiazole, Propiomazine, Valerian, } \\
\text { Dexmedetomidine }\end{array}$ \\
\hline Antidepressants & N06A & $\begin{array}{l}\text { Clomipramine, Amitriptyline, Nortriptyline, Maprotiline, Fluoxetine, Citalopram, Paroxetine, Sertraline, } \\
\text { Fluvoxamine, Escitalopram, Moclobemide, Mianserin, Mirtazapine, Bupropion, Venlafaxine, Reboxetine, } \\
\text { Duloxetine, Agomelatine, Vortioxetine }\end{array}$ \\
\hline Psychostimulants & N06B & $\begin{array}{l}\text { Dexamphetamine, Methylphenidate, Modafinil, Atomoxetine, Lisdexamfetamine, Caffeine, Piracetam, } \\
\text { Linopirdine, Idebenone }\end{array}$ \\
\hline
\end{tabular}

Table S2 Adverse pregnancy outcomes in singleton births to women with autism, without medication during pregnancy, Sweden, 2006-2014.

\begin{tabular}{|c|c|c|c|c|c|}
\hline \multicolumn{2}{|c|}{ Outcome variables } & \multirow{2}{*}{$\begin{array}{l}\text { Cases in women } \\
\text { with autism } \\
(\mathbf{n}=1,189)\end{array}$} & \multirow{2}{*}{$\begin{array}{l}\begin{array}{l}\text { Cases in } \\
\text { population controls } \\
(\mathbf{n}=\mathbf{8 , 0 8 , 5 7 0 )}\end{array} \\
36,915(4.6)\end{array}$} & \multirow{2}{*}{$\begin{array}{l}\text { Crude OR; } \\
95 \% \mathrm{Cl} \\
1.43 ; 1.13-1.80\end{array}$} & \multirow{2}{*}{$\begin{array}{l}\text { Adjusted OR; } \\
95 \% \mathrm{Cl} \\
1.32 ; 1.04-1.67\end{array}$} \\
\hline Preterm birth & Preterm birth, all & & & & \\
\hline & Preterm birth $<28$ weeks & $5(0.4)$ & $1,965(0.2)$ & $1.73 ; 0.72-4.18$ & $1.66 ; 0.69-4.00$ \\
\hline & Preterm birth 28 to $<32$ weeks & $6(0.5)$ & $3,4060(0.4)$ & $1.20 ; 0.54-2.68$ & I.12; 0.50-2.50 \\
\hline & Preterm birth 32 to $<37$ weeks & $65(5.5)$ & $31,544(3.9)$ & $I .42 ; I . I I-I .83$ & $1.31 ; 1.02-1.69$ \\
\hline & Spontaneous preterm birth ${ }^{\mathrm{b}}$ & $46(3.9)$ & $22,940(2.8)$ & $1.38 ; 1.02-1.85$ & $1.24 ; 0.92-1.67$ \\
\hline & Medically indicated preterm birth ${ }^{\mathrm{b}}$ & $30(2.5)$ & $13,643(1.7)$ & $1.50 ; 1.05-2.17$ & $1.46 ; 1.01-2.10$ \\
\hline Mode of & Cesarean delivery & $199(16.7)$ & $1,30,749(16.2)$ & $1.04 ; 0.90-1.21$ & $1.24 ; 1.06-1.44$ \\
\hline \multirow[t]{3}{*}{ delivery } & Elective cesarean delivery & III (9.3) & $65,467(8.1)$ & I.I7; 0.96-I.42 & $1.45 ; 1.19-1.13$ \\
\hline & Not elective cesarean delivery & $88(7.4)$ & $65,282(8.1)$ & $0.91 ; 0.73-1.13$ & $1.01 ; 0.8 \mathrm{I}-1.26$ \\
\hline & Induction of delivery, all & $203(17.1)$ & $1,05,746(13.1)$ & $1.37 ; 1.18-1.59$ & $1.40 ; 1.20-1.63$ \\
\hline Apgar score & Apgar score $<7$ at 5 minutes & II (0.9) & $9,912(1.2)$ & $0.75 ; 0.42-1.36$ & $0.73 ; 0.40-1.33$ \\
\hline Intrauterine & SGA & $138(11.7)$ & $76,4 I I(9.5)$ & $1.26 ; 1.06-I .5 I$ & $1.23 ; 1.02-1.47$ \\
\hline growth & LGA & $106(9.0)$ & $79,324(9.8)$ & $0.90 ; 0.74-1.10$ & $0.89 ; 0.73-1.10$ \\
\hline Stillbirth & Stillbirth & $5(0.4)$ & $2,383(0.3)$ & I.43; 0.59-3.44 & I.42; 0.59-3.43 \\
\hline Maternal & Preeclampsia & $44(3.7)$ & $21,4 \mid 4(2.6)$ & $1.4 I ; 1.04-1.9 I$ & I.26; 0.93-I.7I \\
\hline complications & Gestational diabetes & $14(1.2)$ & $8,867(I . I)$ & I.08; $0.63-1.82$ & I.36; 0.80-2.32 \\
\hline
\end{tabular}

Notes: Data are $\mathrm{n}(\%)$ unless otherwise specified. Statistically significant risk estimates were italicized and bold. ${ }^{\mathrm{a}} \mathrm{ORs}$ were adjusted for maternal age, country of maternal birth, smoking, body mass index, parity, and year of birth. 'We did not have data on spontaneous vs induced preterm birth in all preterm births, hence numbers do not add up. Abbreviations: LGA, large for gestational age; SGA, small for gestational age. 
Table S3 Adverse pregnancy outcomes in singleton births to women with autism, with psychotropic and antiepileptic medication during pregnancy, Sweden, 2006-2014

\begin{tabular}{|c|c|c|c|c|c|}
\hline \multicolumn{2}{|c|}{ Outcome variables } & \multirow{2}{*}{$\begin{array}{l}\begin{array}{l}\text { Cases in women } \\
\text { with autism } \\
(n=1,007)\end{array} \\
7 \mid(7.1)\end{array}$} & \multirow{2}{*}{$\begin{array}{l}\text { Cases in } \\
\text { population controls } \\
(n=67,374)\end{array}$} & \multirow{2}{*}{$\begin{array}{l}\text { Crude OR; } \\
\text { 95\% Cl } \\
1.08 ; 0.85-1.38\end{array}$} & \multirow{2}{*}{$\begin{array}{l}\text { Adjusted OR; } \\
95 \% \mathrm{Cl} \\
1.02 ; 0.80-1.30\end{array}$} \\
\hline Preterm birth & Preterm birth, all & & & & \\
\hline & Preterm birth $<28$ weeks & $I(0.1)$ & $183(0.2)$ & $0.36 ; 0.05-2.61$ & $0.35 ; 0.05-2.79$ \\
\hline & Preterm birth 28 to $<32$ weeks & $7(0.7)$ & $399(0.6)$ & I.I8; 0.56-2.49 & I. $12 ; 0.53-2.37$ \\
\hline & Preterm birth 32 to $<37$ weeks & $63(6.3)$ & $3,844(5.7)$ & I.10; 0.85-1.43 & $1.04 ; 0.80-1.34$ \\
\hline & Spontaneous preterm birth ${ }^{\mathrm{b}}$ & $4 I(4 . I)$ & $2,408(3.6)$ & I.14; 0.84-I.57 & $1.06 ; 0.77-1.46$ \\
\hline & Medically indicated preterm birth ${ }^{\mathrm{b}}$ & $29(2.9)$ & $1,969(2.9)$ & $0.98 ; 0.68-1.43$ & $0.95 ; 0.66-1.38$ \\
\hline \multirow[t]{4}{*}{ Mode of delivery } & Cesarean delivery & $196(19.5)$ & I5,033 (22.3) & $0.84 ; 0.72-0.98$ & $0.98 ; 0.84-1.15$ \\
\hline & Elective cesarean delivery & $106(10.5)$ & $8,377(12.4)$ & $0.83 ; 0.68-1.02$ & $1.02 ; 0.84-1.26$ \\
\hline & Not elective cesarean delivery & $90(8.9)$ & $6,656(9.9)$ & $0.90 ; 0.72-1.11$ & $0.94 ; 0.75-1.17$ \\
\hline & Induction of delivery, all & $228(22.6)$ & $|2,09|(\mid 7.9)$ & $1.34 ; 1.15-1.55$ & $1.33 ; 1.14-1.55$ \\
\hline Apgar score & Apgar score $<7$ at 5 minutes & $23(2.3)$ & $1,319(2.0)$ & I.17; 0.77-1.78 & $1.14 ; 0.75-1.73$ \\
\hline Intrauterine & SGA & $112(11.2)$ & $6,666(9.5)$ & $1.14 ; 1.06-1.51$ & $1.05 ; 0.86-1.28$ \\
\hline growth & LGA & $109(9.0)$ & $7,396(9.8)$ & $0.98 ; 0.80-1.20$ & $1.05 ; 0.86-1.29$ \\
\hline Stillbirth & Stillbirth & I $(0.1)$ & $245(0.4)$ & $0.27 ; 0.04-1.94$ & $0.26 ; 0.04-1.88$ \\
\hline Maternal & Preeclampsia & $47(4.7)$ & $2,299(3.4)$ & $1.39 ; 1.03-1.86$ & I.29; 0.95-I.74 \\
\hline complications & Gestational diabetes & $13(1.3)$ & $\mathrm{I}, 052(\mathrm{I} .3)$ & $0.82 ; 0.48-1.43$ & $0.99 ; 0.56-1.72$ \\
\hline
\end{tabular}

Notes: Data are $\mathrm{n}(\%)$ unless otherwise specified. Statistically significant risk estimates are italicized and bold. a ORs were adjusted for maternal age, country of maternal birth,

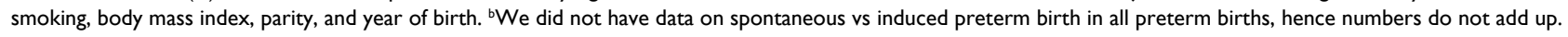
Abbreviations: LGA, large for gestational age; SGA, small for gestational age.

\section{Publish your work in this journal}

Clinical Epidemiology is an international, peer-reviewed, open access, online journal focusing on disease and drug epidemiology, identification of risk factors and screening procedures to develop optimal preventative initiatives and programs. Specific topics include: diagnosis, prognosis, treatment, screening, prevention, risk factor modification,

Submit your manuscript here: https://www.dovepress.com/clinical-epidemiology-journal systematic reviews, risk and safety of medical interventions, epidemiology and biostatistical methods, and evaluation of guidelines, translational medicine, health policies and economic evaluations. The manuscript management system is completely online and includes a very quick and fair peer-review system, which is all easy to use. 